University of Wollongong

Research Online

Australian Institute for Innovative Materials -

Papers

Australian Institute for Innovative Materials

$1-1-2018$

\title{
Solid-State Poly(ionic liquid) Gels for Simultaneous CO2 Adsorption and Electrochemical Reduction
}

Tania Benedetti Goncales

University of Wollongong, taniaben@uow.edu.au

Sina Naficy

University of Sydney, snaficy@uow.edu.au

Ashley Walker

University of Wollongong, ashleyw@uow.edu.au

David L. Officer

University of Wollongong, davido@uow.edu.au

Gordon G. Wallace

University of Wollongong, gwallace@uow.edu.au

See next page for additional authors

Follow this and additional works at: https://ro.uow.edu.au/aiimpapers

Part of the Engineering Commons, and the Physical Sciences and Mathematics Commons

Research Online is the open access institutional repository for the University of Wollongong. For further information contact the UOW Library: research-pubs@uow.edu.au 


\title{
Solid-State Poly(ionic liquid) Gels for Simultaneous CO2 Adsorption and Electrochemical Reduction
}

\author{
Abstract \\ Managing carbon dioxide (CO2) released from large-scale industrial processes is of great importance, yet \\ there remain significant technical challenges. Herein, the fabrication of 1- mm-thick solid-state \\ electrochemical devices based on poly- (ionic liquid) ionogels with embedded electrodes capable of both \\ adsorption and electrochemical reduction of $\mathrm{CO} 2$ is reported. The ionogels are prepared via radical \\ polymerization and chemical crosslinking of a vinyl imidazolium trifluoromethanesulfonimide ionic liquid \\ monomer in the presence of additional ionic liquids (ILs) that act as swelling agents and enhance ionic \\ conductivity. The effects of the ILs concentration and the degree of crosslinking on the mechanical \\ properties, conductivity, and $\mathrm{CO} 2$ adsorption of the ionogels are investigated. The ionogels are shown to \\ have ionic conductivities as high as $0.6 \mathrm{mScm} @ 1$. The results of quartz crystal microbalance analyses \\ demonstrates that the CO2 adsorption of the ionogels reaches up to \&22 mgg@1, which is 10-fold higher \\ than that of their native ionic liquid. Moreover, the ionogels are easily recoverable after $\mathrm{CO} 2$ adsorption. \\ The flexibility, conductivity, and $\mathrm{CO} 2$ capture capacity of this system can be controlled by the crosslinking \\ ratio and ionic liquid content of the ionogels. This electrochemical device has the potential to be used in \\ large scale plants for capturing $\mathrm{CO} 2$ for further electrochemical reactions.

\section{Disciplines} \\ Engineering | Physical Sciences and Mathematics

\section{Publication Details} \\ Benedetti Goncales, T., Naficy, S., Walker, A., Officer, D. L., Wallace, G. G. \& Dehghani, F. (2018). Solid-State \\ Poly(ionic liquid) Gels for Simultaneous $\mathrm{CO} 2$ Adsorption and Electrochemical Reduction. Energy \\ Technology: generation, conversion, storage, distribution, 6 (4), 702-709.
}

\section{Authors}

Tania Benedetti Goncales, Sina Naficy, Ashley Walker, David L. Officer, Gordon G. Wallace, and Fariba Dehghani 


\title{
Solid-State Poly(ionic liquid) Gels for Simultaneous $\mathrm{CO}_{2}$ Adsorption and Electrochemical Reduction
}

\author{
Tania Benedetti, ${ }^{[\mathrm{a}, \mathrm{c}]}$ Sina Naficy, ${ }^{* \mathrm{~b}]}$ Ashley Walker, ${ }^{[\mathrm{a}]}$ David L. Officer, ${ }^{[\mathrm{a}]}$ \\ Gordon G. Wallace, ${ }^{*[\mathrm{a}]}$ and Fariba Dehghani ${ }^{[\mathrm{b}]}$
}

\begin{abstract}
Managing carbon dioxide $\left(\mathrm{CO}_{2}\right)$ released from large-scale industrial processes is of great importance, yet there remain significant technical challenges. Herein, the fabrication of 1mm-thick solid-state electrochemical devices based on poly(ionic liquid) ionogels with embedded electrodes capable of both adsorption and electrochemical reduction of $\mathrm{CO}_{2}$ is reported. The ionogels are prepared via radical polymerization and chemical crosslinking of a vinyl imidazolium trifluoromethanesulfonimide ionic liquid monomer in the presence of additional ionic liquids (ILs) that act as swelling agents and enhance ionic conductivity. The effects of the ILs concentration and the degree of crosslinking on the mechanical prop-
\end{abstract}

erties, conductivity, and $\mathrm{CO}_{2}$ adsorption of the ionogels are investigated. The ionogels are shown to have ionic conductivities as high as $0.6 \mathrm{mScm}^{-1}$. The results of quartz crystal microbalance analyses demonstrates that the $\mathrm{CO}_{2}$ adsorption of the ionogels reaches up to $\approx 22 \mathrm{mgg}^{-1}$, which is 10 -fold higher than that of their native ionic liquid. Moreover, the ionogels are easily recoverable after $\mathrm{CO}_{2}$ adsorption. The flexibility, conductivity, and $\mathrm{CO}_{2}$ capture capacity of this system can be controlled by the crosslinking ratio and ionic liquid content of the ionogels. This electrochemical device has the potential to be used in large scale plants for capturing $\mathrm{CO}_{2}$ for further electrochemical reactions.

\section{Introduction}

Carbon dioxide $\left(\mathrm{CO}_{2}\right)$ is the primary greenhouse gas and its emission has continuously increased because of the extensive use of fossil fuels, thereby causing unpredictable changes in the environment. While many industries are looking for alternative sources of energy to lower $\mathrm{CO}_{2}$ emissions, it is also rational to capture and utilize this gas for other value-added purposes. The post-combustion gases released by power plants account for $40 \%$ of the total $\mathrm{CO}_{2}$ emission, and currently there are only a few methods for $\mathrm{CO}_{2}$ capture and utilization. ${ }^{[1]}$

The selectivity, high adsorption capacity, and ability to regenerate the adsorbed gas are desirable properties that need to be considered when designing a system for capturing $\mathrm{CO}_{2}{ }^{[2]}$ Currently, aqueous solutions of amines, such as monoethanolamine, are used on a commercial scale for $\mathrm{CO}_{2}$ capture from natural gas production industries. However, the shortcomings of these systems include the high cost of the process due to the high heat capacity of water ${ }^{[3,4]}$ excessive pressure-induced loss of absorbent, the corrosive properties of the materials, and thermal degradation. Solid adsorbents have been used as alternatives to solve some of the problems associated with aqueous alkanolamine solutions. ${ }^{[5]}$ Metal organic frameworks (MOFs) ${ }^{[6,7]}$ zeolites,${ }^{[8]}$ and polymers with $\mathrm{CO}_{2}$-adsorbing functional groups are examples of the solid adsorbents that have been proposed for $\mathrm{CO}_{2}$ capture. ${ }^{[9]}$ However, while $\mathrm{CO}_{2}$ capture by MOFs and zeolites can range from $\approx 0.5$ to $400 \mathrm{mgg}^{-1}$ at 1 bar and $273 \mathrm{~K}$, it is difficult to utilize these systems on a large scale because of their brittleness and cumbersome processing.
Recently, ionic liquids (ILs) have been highlighted as promising materials for their capacity to selectively absorb 1 to $2 \mathrm{mg} \mathrm{g}^{-1} \mathrm{CO}_{2}$ at 1 bar. $^{[10-13]}$ ILs exhibit high thermal and chemical stability, ${ }^{[14-17]}$ and can be easily incorporated into solid substrates such as porous silica to develop solid adsorbents with improved performance due to their higher surface area. ${ }^{[18-21]}$ However, these systems can only operate at low pressures in order to prevent IL loss during the recovery and separation process. ${ }^{[22]}$ Poly(ionic liquids) (PILs), polymers derived from monomers based on ILs, have also been investigated for $\mathrm{CO}_{2}$ capturing. ${ }^{[23-26]}$ PILs are ionically conductive and their $\mathrm{CO}_{2}$ adsorption capacity is between 2 and $20 \mathrm{mg} \mathrm{g}^{-1}$, which is higher than their IL counterparts. ${ }^{[2,27-31]}$

\footnotetext{
[a] T. Benedetti, A. Walker, D. L. Officer, G. G. Wallace Intelligent Polymer Research Institute and ARC Centre of Excellence for Electromaterials Science

University of Wollongong Wollongong NSW 2522 (Australia)

E-mail: gwallace@uow.edu.au

[b] S. Naficy, F. Dehghani

School of Chemical and Biomolecular Engineering The University of Sydney, Sydney NSW 2006 (Australia) E-mail: sina.naficy@sydney.edu.au

[c] T. Benedetti

Current address: School of Chemistry

The University of New South Wales Sydney, NSW 2052 (Australia)

$\square$ Supporting information and the ORCID identification number(s) for the

(iD author(s) of this article can be found under: https://doi.org/10.1002/ente.201700679.
} 
In addition to passive $\mathrm{CO}_{2}$ capture, it is useful to convert the adsorbed gas to valuable reagents. As an example, Zhang et al. used a sulfonate-based MOF with embedded Lewis acidic sites to produce cyclic carbonates through the reaction of epoxides and the captured $\mathrm{CO}_{2}$. The conversion yield of cyclic carbonate products was between $40 \%$ and $99 \% .{ }^{[32]}$ Other catalysts such as ferroporphyrin, copper nanocrystals, transient metal oxides, and palladium have also been used for the conversion of $\mathrm{CO}_{2}$ into other valuable products and feedstocks via electrochemical reduction. ${ }^{[33-36]}$

In this study, we have developed a new strategy in which a solid electrolyte system is designed for simultaneous $\mathrm{CO}_{2}$ adsorption and its electrochemical reduction. To this end, we synthesized ionically conductive gels, acting as solid-state electrolytes that are also capable of $\mathrm{CO}_{2}$ adsorption. The ionogels are based on a crosslinked PIL network and an ionic liquid swelling agent, namely 1-ethyl-3-methylimidazolium trifluoromethylsulfonylimide (EMI.TFSI), which is added to the network to enhance the conductivity of the system for electrochemical reactions. By adjusting the IL content and the crosslinking ratio of the ionogels, we are able to control the relevant properties to achieve the desired mechanical stability, ionic conductivity, and $\mathrm{CO}_{2}$ adsorption capacity.

\section{Results and Discussion}

\section{Synthesis of PIL gels}

The full details of the synthesis of reactive monomers and the preparation of the ionogels are provided in the Experimental Section and schematically presented in Scheme 1.

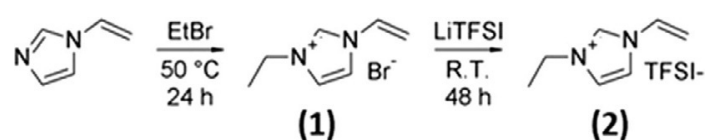

Scheme 1. Synthesis of EVI.TFSI monomer (2).

Briefly, an intermediate IL monomer (1, Scheme 1) was prepared from the reaction of 1-vinylimidazole and bromoethane, which was subjected to an ion exchange process to obtain the final 1-ethyl-3-vinylimidazolium trifluoromethanesulfonimide (EVI.TFSI) monomer (2, Scheme 1).
PIL ionogels were then prepared via the radical polymerization of the EVI.TFSI monomer in the presence of the crosslinking agent and EMI.TFSI. The latter was used as a swelling agent for the PIL ionogels. As shown in Table 1, nine different compositions of ionogels were synthesized and the effects of IL content and the crosslinking ratio on the mechanical properties, ionic conductivity, and $\mathrm{CO}_{2}$ adsorption of the ionogels were examined. Various solid structures were fabricated from these ionogels because of their robust mechanical properties (Figure 1). As an example, Figure $1 \mathrm{~b}$ demonstrates the formation of a hollow and flexible tubular structure from ionogel $\mathrm{IGX}_{10} \mathrm{IL}_{300}$. Such tubular structures could be used in large scale plants for capturing $\mathrm{CO}_{2}$ in exhaust pipes.

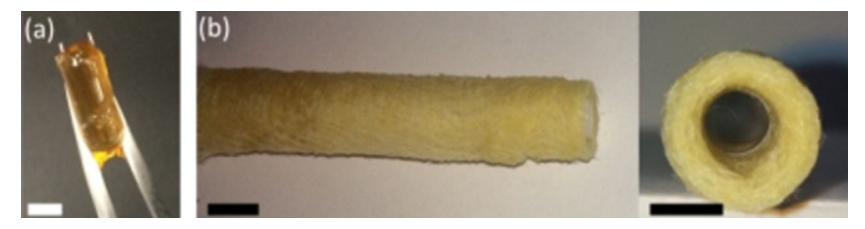

Figure 1. a) An example of a cylindrical POIL gel and b) a hollow tube made of POIL gel infused in cotton. Scale bars are $2 \mathrm{~mm}$ in (a) and $5 \mathrm{~mm}$ in (b).

\section{Mechanical properties of PIL gels}

The stiffness of the prepared PIL gels was measured using indentation testing. ${ }^{[37]}$ In Figure 2, the Young's moduli of the PIL gels are presented as a function of the amount of EMI.TFSI swelling agent in the ionogels (Figure $2 \mathrm{a}$ ) and the degree of crosslinking (Figure $2 \mathrm{~b}$ ). The crosslinked PIL network with no EMI.TFSI had a Young's modulus of $90.7 \pm 21.8 \mathrm{kPa}$. The PIL network swollen in EMI.TFSI, on the other hand, exhibited a considerable decrease in Young's modulus, with the stiffness continuing to drop as the amount of EMI.TFSI in the ionogel was increased (Figure 2a). At $40 \%$ EMI.TFSI in the ionogel, the Young's modulus decreased dramatically to $12.3 \pm 3.1 \mathrm{kPa}$. In the ionogel network swollen with EMI.TFSI, the IL molecules acted as a diluent, hence decreasing the mechanical resistance of the network against external forces. In a swollen elastomeric network, the diluting effect of the swelling agent on the mechanical stiffness of the network can be summarized by Equation (1): $:^{[38]}$

$E \propto Q^{-1 / 3}$

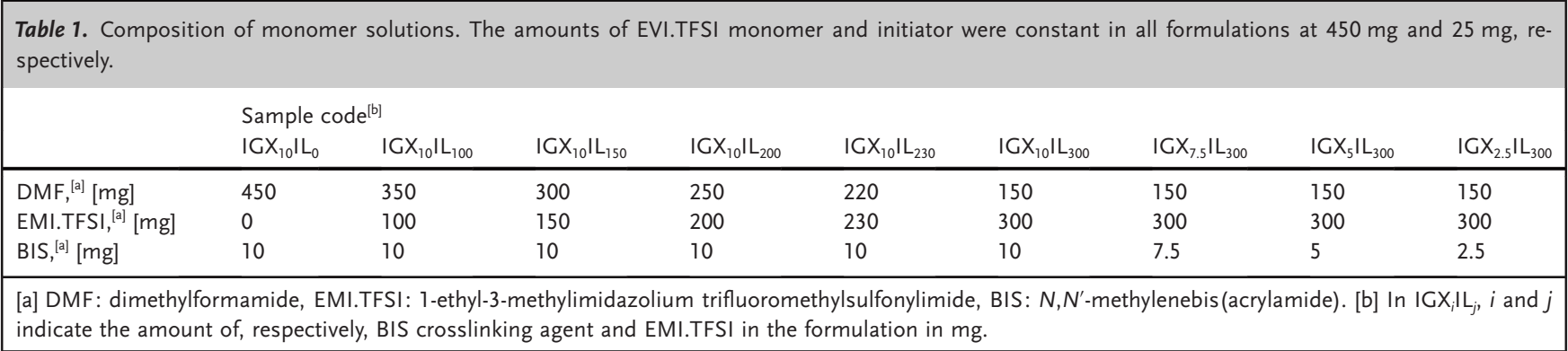



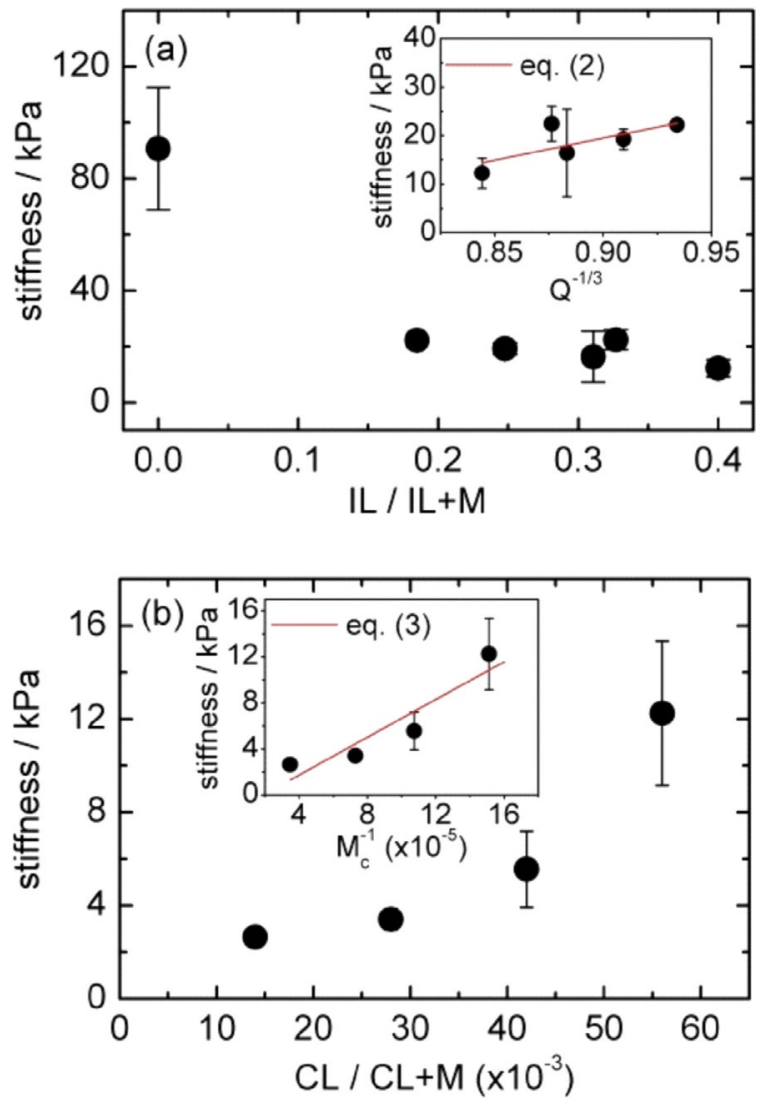

Figure 2. a) Stiffness of ionogels as a function of IL molar ratio and b) crosslinking agent molar ratio. IL, M, and CL refer to EMI.TFSI IL, EVI.TFSI monomer, and BIS crosslinking agent, respectively.

where $E$ is the Young's modulus of the swollen network and $Q$ is the volumetric swelling ratio. The results in Figure 2 a show that the Young's modulus of PIL gels is linearly proportional to the inverse of the cubic root of the swelling ratio of the gels, suggesting that the EMI.TFSI was purely a diluting factor in the network. It is important to note that the Young's modulus of an unswollen PIL network did not fit with this trend due to the fact that at ambient conditions the PIL polymer chains in the unswollen network depart from the elastomeric state towards the glassy state. The glass transition temperature $\left(T_{\mathrm{g}}\right)$ of the pure PIL based on EVI.TFSI monomers was $110^{\circ} \mathrm{C}$, which is significantly higher than the ambient temperature at which the mechanical testing was conducted. The $T_{\mathrm{g}}$ of ionogels varied with the amount of EMI.TFSI in their network, clearly following the rule of mixture (Supporting Information). The observation of a single $T_{\mathrm{g}}$ for ionogels suggests that the interaction between PIL and EMI.TFSI is merely physical mixing with EMI.TFSI having a plasticizing effect.

The data in Figure $2 \mathrm{~b}$ demonstrate a correlation between the degree of crosslinking and the Young's modulus of the ionogels, where the modulus continuously increases with crosslinking ratio. The Young's modulus increased from $2.65 \mathrm{kPa}$ to $12.25 \mathrm{kPa}$ when the degree of crosslinking was raised from $1.4 \mathrm{~mol} \%$ to $5.6 \mathrm{~mol} \%$. The increase in Young's modulus was inversely proportional to the molecular weight between two adjacent crosslinking points (i.e., ${M_{\mathrm{c}}}^{-1}$ ) as depicted in Figure $2 \mathrm{~b}$ and Equation (2): ${ }^{[38]}$

$E \propto M_{\mathrm{c}^{-1}}$

Equation (2) is valid for an ideal elastomeric network, which suggests that the mechanical behavior of the ionogels resembles an elastomeric network.

\section{Conductivity of PIL gels}

A critical aspect of these ionogels is their ionic conductivity, which can be utilized for the development of PIL gels in functional devices. The ionic conductivity of the PIL gels was measured using a two-electrode set-up. Figure 3 shows that the ionic conductivity of PIL gels was a function of the degree of crosslinking and ionic composition of the ionogels, as both these factors impact the mobility of the ionic species. The ionic conductivity was elevated by increasing the IL content and also by decreasing the degree of crosslinking. The impact of the IL content was more paramount than the crosslinking ratio: the conductivity was increased 15 fold when the IL content was increased by a factor of two, while it was elevated only 2.6 fold when the crosslinking ratio was
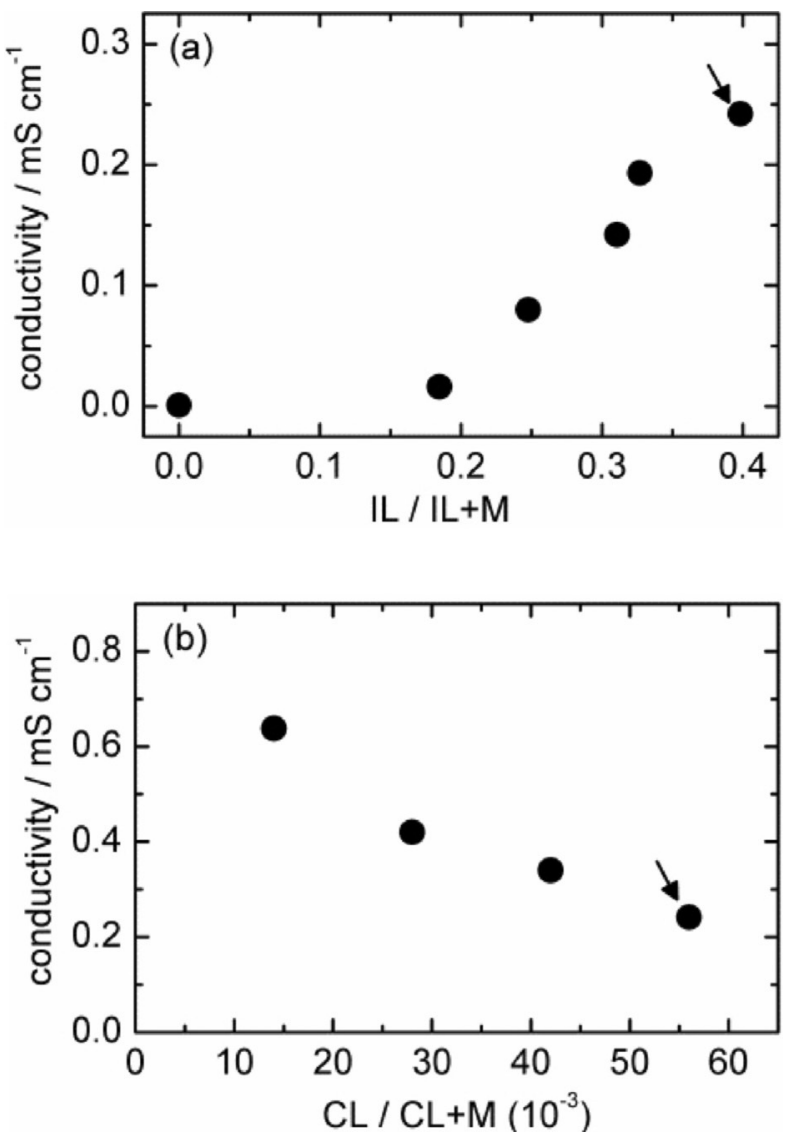

Figure 3. a) Conductivity of ionogels as a function of IL molar ratio and b) crosslinking agent molar ratio. Arrows indicate the same sample. IL, M, and $\mathrm{CL}$ refer to EMI.TFSI, EVI.TFSI monomer, and BIS crosslinking agent, respectively. The error bars are smaller than the size of the data points. 
reduced by 4.3 fold. The addition of IL reduces the $T_{\mathrm{g}}$ of the network and increases the chain mobility as well as the relative number of mobile ionic species within the gel. Both these factors enhance mobility of ions and increase the ionic conductivity of the network. Similarly, reducing the crosslinking ratio increases the chain mobility and facilitates the mobility of the ionic species, which results in higher ionic conductivity.

\section{$\mathrm{CO}_{2}$ capture}

The effects of IL content and of the degree of crosslinking on the $\mathrm{CO}_{2}$ adsorption of the PIL gels were studied using quartz crystal microbalance with dissipation monitoring (QCM-D) and thermogravimetric analysis (TGA). For QCM tests, thin films of ionogels with different composition were deposited over the quartz sensors. Then, the changes in frequency and dissipation at different overtones ranging from 3 to 11 were measured during the passage of $\mathrm{N}_{2}, \mathrm{CO}_{2}$, or under vacuum inside the QCM flow chamber. No frequency or dissipation change was observed during the passage of $\mathrm{N}_{2}$, meaning that the PIL gels did not adsorb $\mathrm{N}_{2}$ gas. However, during the passage of $\mathrm{CO}_{2}$, the frequency decreased and dissipation increased for all ionogel compositions (Figure $4 \mathrm{a}$ ).

The fact that the changes observed in the dissipation $(D)$ were larger than those observed for the frequency $(f)$ and
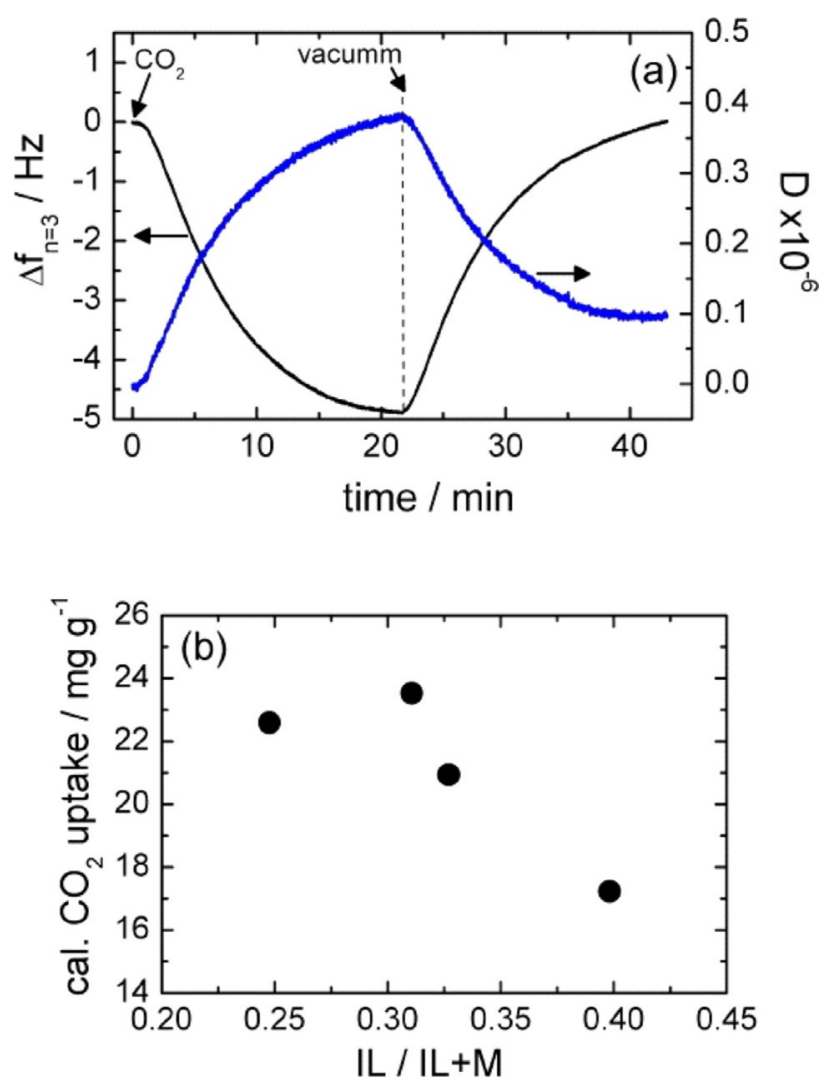

Figure 4. a) An example of frequency and dissipation change measured by QCM-D over time under $\mathrm{CO}_{2}$ flow. b) Calculated mass change due to $\mathrm{CO}_{2}$ adsorption at equilibrium as a function of IL molar ratio. IL and $\mathrm{M}$ refer to EMI.TFSI IL and EVI.TFSI monomer, respectively. within different harmonics means that the viscoelastic properties of the films were a function of $\mathrm{CO}_{2}$ adsorption. Therefore, the mass change due to gas adsorption cannot be directly derived from the frequency change using the Sauerbrey equation (see Experimental Section). The $f$ and $D$ changes measured for different harmonics were then fitted using the Kevin-Voigt model to obtain the mass changes. The calculated mass change $(\Delta m)$ as a function of time $(t)$ was fitted using the pseudo first-order adsorption Equation(3) to obtain the mass of adsorbed $\mathrm{CO}_{2}$ at equilibrium $\left(q_{\mathrm{e}}\right)$ :

$q_{\mathrm{t}}=q_{\mathrm{e}}\left(1-e^{k_{1} t}\right)$

The pseudo-first order equation is used to describe those systems in which the sorption process is non-reactive. ${ }^{[39]}$ The process of $\mathrm{CO}_{2}$ adsorption by imidazolium ILs is most likely physical and non-reactive. ${ }^{[40]}$ All $\Delta m$ versus $t$ curves were fitted to a linear correlation $\left(R^{2}=0.99\right)$. The calculated $\mathrm{CO}_{2}$ adsorptions at equilibrium normalized to the mass of ionogel, $q_{\mathrm{e}}$, are presented in Figure $4 \mathrm{~b}$, as a function of the amount of IL in the ionogels. The adsorption capacity approached $24 \mathrm{mgg}^{-1}$ for the $\mathrm{IGX}_{10} \mathrm{IL}_{150}$ ionogel, which is comparable to the adsorption of mesoporous styryl-crosslinked vinylimidazolium-based PILs with TFSI anions. ${ }^{[41]}$ Initially, increasing the IL content slightly increased the adsorption capacity, which can be ascribed to easier gas diffusion in the more swollen ionogels. However, with further increasing of IL content, the adsorption capacity significantly decreased due to a higher mobility of ions at higher degrees of swelling. The evaluation of the effect of crosslinking ratio on $\mathrm{CO}_{2}$ adsorption of ionogels using QCM-D technique was inconclusive due to the dominant viscose properties of ionogels with low crosslinking ratio.

While QCM-D provides information on $\mathrm{CO}_{2}$ adsorption of ionogels at the microscale, such information is not always directly relevant to the macroscale $\mathrm{CO}_{2}$ adsorption of ionogels where gas diffusion becomes an important limiting factor. To investigate the bulk $\mathrm{CO}_{2}$ adsorption properties of PIL gels, TGA was performed on the ionogels listed in Table 1. The isothermal $\mathrm{CO}_{2}$ adsorption of ionogels at $50^{\circ} \mathrm{C}$ was measured from their mass change when samples were exposed to $100 \mathrm{~mL} \mathrm{~min}^{-1} \mathrm{CO}_{2}$ flow. For all ionogels an immediate increase in mass was detected by switching the gas from $\mathrm{N}_{2}$ to $\mathrm{CO}_{2}$. This mass increase was reversible when gas was switched back to $\mathrm{N}_{2}$. Figure 5 shows the $\mathrm{CO}_{2}$ adsorbed by the ionogels as a function of their IL content (Figure $5 \mathrm{a}$ ), and crosslinking ratio (Figure $5 \mathrm{~b}$ ). In general, the $\mathrm{CO}_{2}$ adsorption capacity of the ionogels as a function of IL content obtained by TGA measurements was much lower than that of QCMD measurements. This effect was due to the significant difference in sample sizes between QCM-D $\left(\approx 50 \mu \mathrm{g} \mathrm{cm}^{-2}\right)$ and TGA $\left(\approx 600 \mathrm{mg} \mathrm{cm}^{-2}\right)$.

The considerably larger sample size used in TGA measurements significantly reduced the access of $\mathrm{CO}_{2}$ gas to the bulk of the ionogels. This behavior was also confirmed by comparing the profile of $\mathrm{CO}_{2}$ adsorption of TGA-tested ionogels as a function of IL content in Figure 5 a with those tested with 

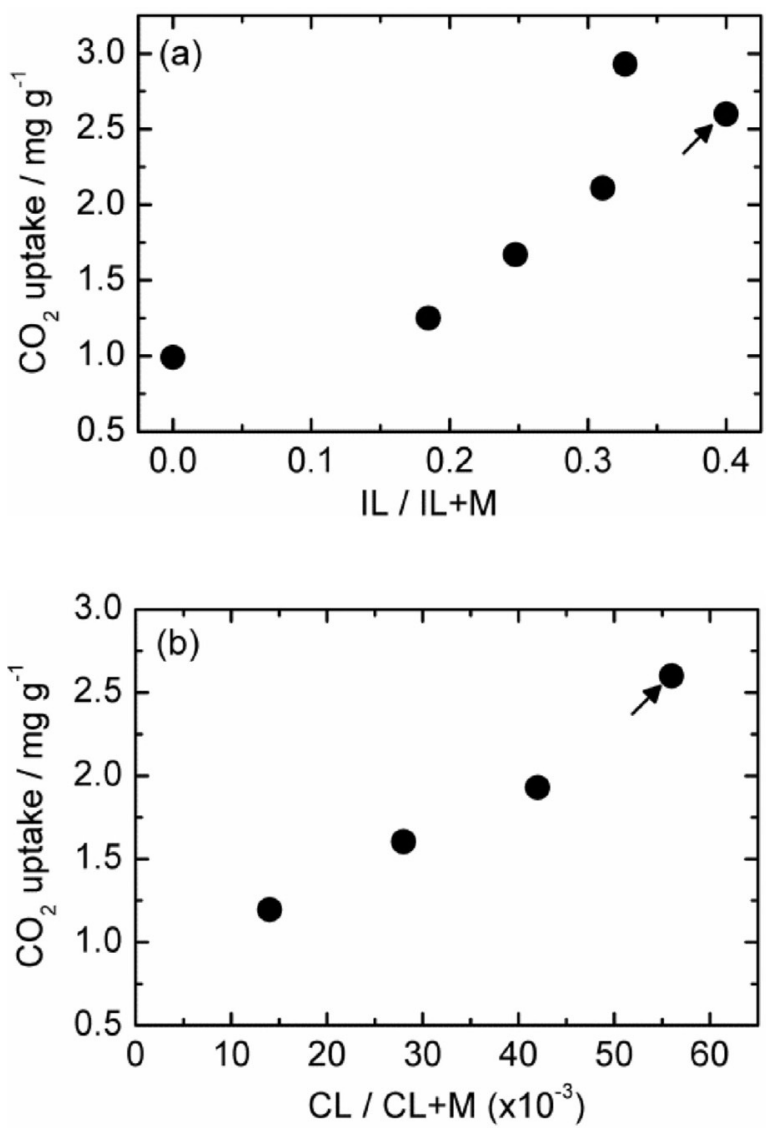

Figure 5. Measured mass change due to $\mathrm{CO}_{2}$ adsorption at equilibrium measured by TGA as a function of a) IL and b) crosslinking molar ratios in ionogels. Arrows indicate the same sample. IL, M, and CL refer to EMI.TFSI IL, EVI.TFSI monomer, and BIS crosslinking agent, respectively. Error bars are smaller than the size of data points.

QCM-D in Figure 4b. In the case of QCM-D, $\mathrm{CO}_{2}$ adsorption slightly increased by elevating IL content, followed by a continuous decreasing trend. The reduced adsorption of $\mathrm{CO}_{2}$ at higher levels of IL was attributed to higher ion mobility in the swollen ionogels. ${ }^{[22]}$ In addition, the heterogeneous structure of the gel network prevents the continuous rearrangement of charged species to accommodate ionic repulsions. ${ }^{[22]}$ In the TGA measurements, a drop in $\mathrm{CO}_{2}$ adsorption capacity as a function of IL was observed at slightly higher IL content due to slower diffusion of $\mathrm{CO}_{2}$ into the dense and less swollen ionogel structure.

The $\mathrm{CO}_{2}$ adsorption of ionogels as a function of crosslinking ratio followed a similar trend to their conductivity. These measurements were conducted on ionogels with the highest amount of IL content where $\mathrm{CO}_{2}$ diffusion was less restricted by the network of PIL. Therefore, $\mathrm{CO}_{2}$ adsorption decreased continuously with increasing ion mobility because of a decreasing crosslinking ratio. The results of QCM-D and TGA studies show that film thickness plays a key role in the gas adsorption. This limiting effect is less critical for swollen ionogels that facilitate the diffusion of $\mathrm{CO}_{2}$.

\section{Simultaneous $\mathrm{CO}_{2}$ adsorption and reduction}

For $\mathrm{CO}_{2}$ capture and electrochemical reduction, the gel must combine both large adsorption capacity and high ionic conductivity to function as a solid electrolyte for $\mathrm{CO}_{2}$ reduction. In addition, the mechanical properties of the ionogel must be optimized to achieve a uniform and stable gel layer covering all electrodes. A prototype device was fabricated from the $\mathrm{IGX}_{10} \mathrm{IL}_{200}$ ionogel as the adsorbent and electrolyte, with a platinum counter electrode and silver working and reference electrodes (Figure 6a). Silver wire was used as the working
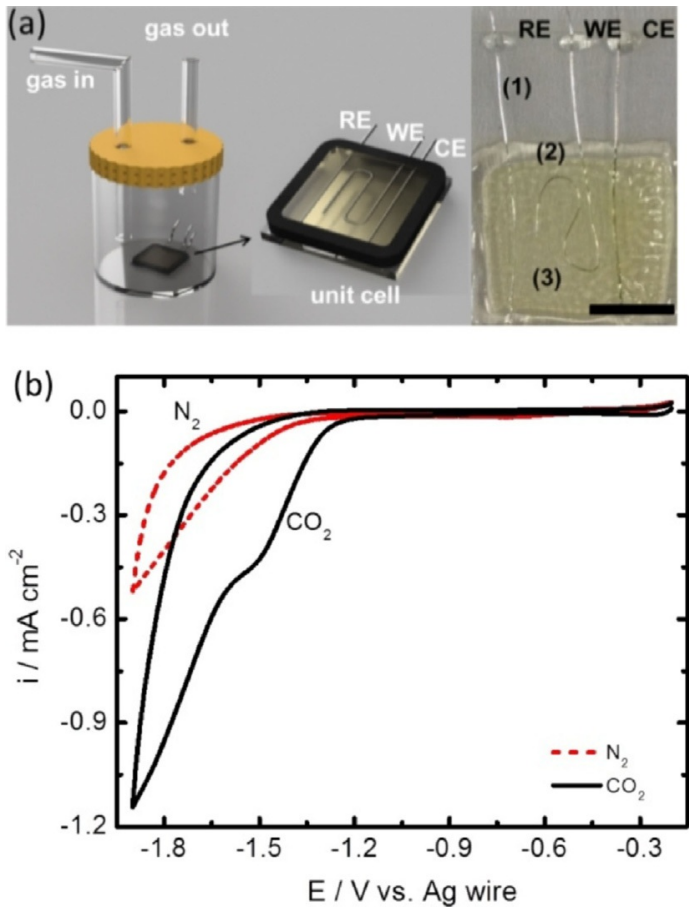

Figure 6. a) Simultaneous $\mathrm{CO}_{2}$ adsorption and reduction using a solid state ionogel device enclosed in a gas chamber. The photograph of the ionogel device highlights the embedded electrodes (1) as reference: RE, working: WE, and counter: CE, the gasket (2) and the ionogel (3). B) The cyclic voltammetry graph shows current vs. voltage profile of the ionogel under $\mathrm{N}_{2}$ (broken line) and $\mathrm{CO}_{2}$ (solid line) blanket. Scale bar is $5 \mathrm{~mm}$.

electrode because this material is known to act as a catalyst for reducing $\mathrm{CO}_{2}$ to $\mathrm{CO}$ at low over potentials with high selectivity and efficiency. ${ }^{[42]} \mathrm{N}_{2}$ and $\mathrm{CO}_{2}$ gases were alternatively passed through the chamber in which the device was placed, and cyclic voltammetry (CV) was performed every 5 min until no further change in the $\mathrm{CV}$ profile was observed. The $\mathrm{CV}$ profiles of the device after the stabilization of the current under $\mathrm{N}_{2}$ and $\mathrm{CO}_{2}$ (Figure 6b) demonstrate that the captured $\mathrm{CO}_{2}$ was able to diffuse through the ionogel and reached the surface of the electrodes. This is evident from a considerable increase in reduction current $(\approx$ $-1.2 \mathrm{~mA} \mathrm{~cm}^{-2}$ ) and a slight decrease in overpotential under $\mathrm{CO}_{2}$ atmosphere compared with $\mathrm{N}_{2}$. The $\mathrm{CV}$ profile under $\mathrm{CO}_{2}$ is similar to results obtained previously using silver elec- 
trodes in aqueous electrolytes containing an imidazolium IL. ${ }^{[43]}$

The reduction current constantly increased during $\mathrm{CO}_{2}$ purging, reaching its maximum after $20 \mathrm{~min}$ of exposure to the gas flow. The observed plateau suggests that the ionogel becomes saturated with $\mathrm{CO}_{2}$ after about 20 min, reaching a stable condition with maximum $\mathrm{CO}_{2}$ conversion to $\mathrm{CO}$. The $\mathrm{CV}$ profiles were reproducible when the gas line was switched between $\mathrm{N}_{2}$ and $\mathrm{CO}_{2}$, suggesting that the device can be continuously regenerated. These results indicate the feasibility of fabricating a solid-state device from suitable ionogels for simultaneous $\mathrm{CO}_{2}$ adsorption and electrochemical reactions.

\section{Conclusion}

An elastic solid-state electrochemical device was designed with dual capacity for the adsorption and electrochemical reduction of $\mathrm{CO}_{2}$. This device was fabricated from robust pol$\mathrm{y}$ (ionic liquid) gels swollen with additional ionic liquid to enhance conductivity. The mechanical properties, conductivity, and $\mathrm{CO}_{2}$ adsorption of ionogels could be controlled by the level of ionic liquid in the ionogels and their crosslinking ratio. High ionic conductivity was achieved by increasing the IL content or reducing the crosslinking ratio. The $\mathrm{CO}_{2}$ uptake of the ionogels showed a slight increase followed by a gradual decline with increasing IL content. Meanwhile, by increasing the crosslinking ratio, the $\mathrm{CO}_{2}$ uptake continuously increased. Simultaneous $\mathrm{CO}_{2}$ adsorption and electrochemical reduction were successfully demonstrated using cyclic voltammetry. This process was reversible and the device was regenerated rapidly after removing $\mathrm{CO}_{2}$. This study provides a method for the fabrication of solid state devices that combine gas adsorption and electrochemical reactions.

\section{Experimental Section}

\section{Materials}

For the IL monomer synthesis, 1-vinylimidazole, bromoethane $\left(\mathrm{C}_{2} \mathrm{H}_{5} \mathrm{Br}\right)$, and lithium trifluoromethanesulfonimide (Li.TFSI), as well as the solvents, methanol $(\mathrm{MeOH})$ and ethyl acetate (EtOAc) were used as received. For polymerization of ionic liquid monomers, $N, N^{\prime}$-methylenebisacrylamide (BIS, crosslinking agent), $\alpha$-ketoglutaric acid (UV initiator), $N, N$-dimethylformamide (DMF, solvent), and 1-ethyl-3-methylimidazolium bis(trifluoromethylsulfonyl)imide (EMI.TFSI, swelling agent IL) were used. All reagents were purchased from Sigma-Aldrich Australia.

\section{Ionic liquid monomers synthesis}

1-Ethyl-3-vinylimidazolium bromide (EVI.Br): ${ }^{[44]}$ To a solution of 1-vinylimidazole $(9.0 \mathrm{~mL}, 100 \mathrm{mmol})$ in EtOAc $(60 \mathrm{~mL})$ was added bromoethane $(14.9 \mathrm{~mL}, 200 \mathrm{mmol})$ and the resulting solution was stirred at $50^{\circ} \mathrm{C}$ for $24 \mathrm{~h}$. The suspension was allowed to cool to room temperature then the precipitate was collected by filtration. The solids were dissolved in $\mathrm{MeOH}$ and the resulting solution was added dropwise to EtOAc $(60 \mathrm{~mL})$. The precipitat- ed product $(15.27 \mathrm{~g}, 75 \%)$ was collected by filtration and used without further purification (1, Scheme 1). See Figure S1 in the Supporting Information for NMR spectra.

${ }^{1} \mathbf{H}$ NMR (400 MHz, D $\left.\mathbf{D}_{2} \mathbf{O}\right) \delta=9.12(\mathrm{~s}, 1 \mathrm{H}) ; 7.85(\mathrm{t}, J 1.8 \mathrm{~Hz}$, $1 \mathrm{H}) ; 7.68(\mathrm{t}, J 1.8 \mathrm{~Hz}, 1 \mathrm{H}) ; 7.23(\mathrm{dd}, J 8.7,15.6 \mathrm{~Hz}, 1 \mathrm{H}) ; 5.88$ $(\mathrm{dd}, J 2.8,15.6 \mathrm{~Hz}, 1 \mathrm{H}) ; 5.51(\mathrm{dd}, J 2.7,8.7 \mathrm{~Hz}, 1 \mathrm{H}) ; 4.36(\mathrm{q}, J$ $7.4 \mathrm{~Hz}, 2 \mathrm{H}) ; 1.61 \mathrm{ppm}(\mathrm{t}, J 7.4 \mathrm{~Hz}, 3 \mathrm{H})$.

${ }^{13} \mathbf{C}$ NMR (100MHz, $\left.\mathbf{D}_{2} \mathbf{O}\right) \delta=134.6 ; 128.9 ; 123.1 ; 120.0 ; 109.9$; $45.8 ; 14.9 \mathrm{ppm}$.

1-Ethyl-3-vinylimidazolium trifluoromethanesulfonimide (EVI.TFSI): ${ }^{[4]}$ To a solution of EVI.Br $(4.06 \mathrm{~g}, 20 \mathrm{mmol})$ in water $(10 \mathrm{~mL})$ was added Li.TFSI $(7.20 \mathrm{~g}, 25 \mathrm{mmol})$. The resulting solution was stirred for $48 \mathrm{~h}$, at room temperature. The lower ionic liquid layer was separated, washed with water, and then dried in vacuo at $50{ }^{\circ} \mathrm{C}$ to give the product $(7.50 \mathrm{~g}, 93 \%)$ as a pale yellow oil, which was used without further purification (2, Scheme 1). See Figure S2 in the Supporting Information for NMR spectra.

${ }^{1}$ H NMR (400MHz, [D $]$ ]DMSO) $\delta=9.46(\mathrm{~s}, 1 \mathrm{H}) ; 8.16(\mathrm{t}, J$ $1.8 \mathrm{~Hz}, 1 \mathrm{H}) ; 7.92(\mathrm{t}, J 1.7 \mathrm{~Hz}, 1 \mathrm{H}) ; 7.27(\mathrm{dd}, J 8.8,15.6 \mathrm{~Hz}, 1 \mathrm{H})$; $5.94(\mathrm{dd}, J 2.4,15.6 \mathrm{~Hz}, 1 \mathrm{H}) ; 5.42(\mathrm{dd}, J 2.3,8.7 \mathrm{~Hz}, 1 \mathrm{H}) ; 4.23$ (q, J $7.3 \mathrm{~Hz}, 2 \mathrm{H}) ; 1.45 \mathrm{ppm}(\mathrm{t}, J 7.3 \mathrm{~Hz}, 3 \mathrm{H})$.

${ }^{13}$ C NMR (100MHz, [D $]$ DMSO) $\delta=135.0 ; 128.8 ; 124.3 ; 122.9$; $121.1 ; 119.1 ; 117.9 ; 114.7 ; 108.6 ; 44.6 ; 14.6$ ppm.

\section{Preparation of ionogels}

The ionogels were prepared via UV radical polymerization of EVI.TFSI (2, Scheme 1) in the presence of BIS crosslinking agent. Briefly, the synthesized EVI.TFSI monomer $(450 \mathrm{mg})$ was added to various amounts of DMF and EMI.TFSI by maintaining the final weight ratio of EVI.TFSI monomer to DMF:EMI.TFSI mixture fixed at 1:1 (i.e. $50 \%$ monomer in solution). To keep the concentration of EVI.TFSI monomer constant throughout the polymerization process and independent of the amount of EMI.TFSI, DMF was used as the diluting solvent and was removed after the polymerization. The BIS crosslinking agent and $\alpha$-ketoglutaric acid UV initiator were added to the solution and fully dissolved. To evaluate the effect of the degree of crosslinking on the properties of ionogels, the molar ratio of BIS crosslinking agent to EVI.TFSI was varied between $5 \times 10^{-3}$ and $2.5 \times$ $10^{-2}$ (BIS:BIS + EVI.TFSI) at a constant DMF:EMI.TFSI weight ratio of 1:2. The effect of EMI.TFSI as a swelling agent on the ionogels' properties was studied by maintaining the crosslinking ratio at $2.5 \times 10^{-2}$ and systematically varying the DMF:EMI.TFSI ratio as shown in Table 1 . Herein, the crosslinked ionogels swollen in EMI.TFSI are denoted as $\mathrm{IGX}_{i} \mathrm{IL}_{j}$, with $i$ and $j$ indicating the amount of BIS crosslinking agent and EMI.TFSI, respective$\mathrm{ly}$, in the formulation in $\mathrm{mg}$.

The hollow ionogel structure shown in Figure $1 \mathrm{~b}$ was made as follows: a cotton fabric was wrapped around a glass rod and then soaked in an IL monomer solution. This solution had the same composition as the $\mathrm{IGX}_{20} \mathrm{IL}_{200}$, except instead of $\alpha$-ketoglutaric acid UV initiator, ammonium persulfate (Sigma) was used as the thermal initiator. After the cotton reached saturation with the IL monomer solution, polymerization was conducted at $60^{\circ} \mathrm{C}$ for $5 \mathrm{~h}$. The middle glass rod was removed after polymerization.

For the mechanical tests and ionic conductivity measurements, respectively, 100 and $50 \mu \mathrm{L}$ of each polymerization solution was inserted into sealed transparent plastic tubes with $0.5 \mathrm{~cm}$ diameter and UV irradiated for $3 \mathrm{~h}$ in a fan-forced UV chamber (Rayonet, UK) equipped with $12 \mathrm{UV}$ bulbs $(300 \mathrm{~nm})$. After polymerization, PIL gels were removed from the tubes and placed 
over glass slides to remove DMF at $120^{\circ} \mathrm{C}$ for $18 \mathrm{~h}$. For $\mathrm{CO}_{2}$ adsorption studies by QCM-D, $30 \mu \mathrm{L}$ of polymerization solution was deposited onto gold-coated AT-cut $5 \mathrm{MHz}$ piezoelectric quartz crystals (14 $\mathrm{mm}$ diameter) (Qsense, Sweden), and the same curing conditions were used. After drying, the excess ionogel was removed from the surface of the quartz sensors with a spatula and wiped with paper (Kimtech Science). The resulting films were thin and uniform enough for QCM measurements. All the films obtained by this procedure were in the range of 40 $50 \mu \mathrm{g} \mathrm{cm}^{-2}$ according to frequency change measurements performed before and after their deposition. TGA was performed on PIL gel films with a thickness of approximately $500 \mu \mathrm{m}$. For cyclic voltammetry experiments, $90 \mu \mathrm{L}$ of the $\mathrm{IGX}_{10} \mathrm{IL}_{200}$ sample was deposited onto a $1.5 \times 1.5 \mathrm{~cm}^{2}$ glass slide on which silver wires as working and reference electrodes and a platinum wire as the counter-electrode were fixed with a UV-cured acrylate glue. The same acrylate glue was used to construct a $2 \mathrm{~mm}$ deep well into which the monomer solution was applied, which was then subjected to the UV irradiation.

\section{Mechanical tests}

The mechanical stiffness of PIL ionogels was measured using a Shimadzu EZ-L mechanical tester (Japan) with a $2 \mathrm{~N}$ load cell. Indentation tests were performed on $5 \mathrm{~mm}$ tall cylindrical PIL ionogels (5 $\mathrm{mm}$ in diameter) using a flat stainless steel indenter (990 $\mu \mathrm{m}$ diameter). At the crosshead speed of $0.1 \mathrm{~mm} \mathrm{~min}^{-1}$, the indenter moved $100 \mu \mathrm{m}$ from the contact point at the surface of the ionogels. The resulting force versus deformation linear curves were used to calculate the PIL ionogels' Young's modulus $(E)^{[37]}$

$F=(8 / 3) a E d$

Here, $F$ and $d$ are force and displacement recorded from the indentation tests and $a$ is the radius of the indenter tip. Measurements were repeated five times.

\section{lonic conductivity measurements}

Ionic conductivity tests were carried out on $\approx 250 \mu \mathrm{m}$ thick ionogel samples placed between two $0.07 \mathrm{~cm}^{2}$ glassy carbon electrodes. The resistance was measured under an applied $0 \mathrm{~V}$ oscillating at $10 \mathrm{kHz}$ and $0.01 \mathrm{~V}$ amplitude. The resistance was then converted into ionic conductivity according to:

$\sigma=L / R A$

where $\sigma$ is the ionic conductivity $\left(\mathrm{Scm}^{-1}\right), L$ is the distance between the two electrodes $(\mathrm{cm}), R$ is the measured resistance $(\Omega)$, and $A$ is the electrode surface area $\left(\mathrm{cm}^{2}\right)$. Measurements were repeated three times.

\section{$\mathrm{CO}_{2}$ adsorption measurements by QCM-D}

A Qsense (model E4, Sweden) instrument was used for the measurements of $\mathrm{CO}_{2}$ adsorption. The quartz sensor containing the deposited ionogel $(\approx 50 \mu \mathrm{g})$ was placed in the QCM-D flow cell (QSense, Sweden) and connected to a gas bag (Sigma-Aldrich) containing $\mathrm{N}_{2}$ or $\mathrm{CO}_{2}$ at the inlet side and to a peristaltic pump at the outlet side, pulling the gas at $1 \mathrm{~mL} \mathrm{~min}^{-1}$. Initially, air inside the chamber was removed by closing the inlet and evacuating the chamber until no change in frequency or dissipation was observed. Then, $\mathrm{N}_{2}$ or $\mathrm{CO}_{2}$ was allowed to flow through the chamber. The adsorption capacity of $\mathrm{IGX}_{10} \mathrm{IL}_{0}$ and $\mathrm{IGX}_{10} \mathrm{IL}_{100}$ was not analyzed with $\mathrm{QCM}$ as it was not possible to obtain a uniformly thin film due to the high stiffness of these samples. The experiment was initiated with the valve in the gas bag closed, so any gas in the system was removed, followed by opening the valve to let the $\mathrm{N}_{2}$ or $\mathrm{CO}_{2}$ gas flow. The frequency $(f)$ and dissipation $(D)$ changes from the 3rd to 11th harmonics $(n)$ were recorded during the processes.

For the mass of deposited ionogel, the $f$ and $D$ at the different harmonics were measured for the quartz sensors before and after ionogel deposition. As the $D$ values were not significantly different for the different harmonics (less than $5 \%$ of $f$ changes), the films were sufficiently thin to be considered piezoelectric rigid and the Sauerbrey equation was used to calculate the mass of the deposited material. ${ }^{[46]}$

$\Delta f_{n}=-\Delta m / C$

where $C$ is the mass sensitivity $\left(17.7 \mathrm{ng} \mathrm{cm}^{-2} \mathrm{~Hz}^{-1}\right)$.

The $f$ and $D$ changes due to $\mathrm{CO}_{2}$ adsorption were fitted using the Kevin-Voigt model to obtain the mass changes as was previously done for the study of water vapor adsorption by PIL/IL films. ${ }^{[47]}$

\section{Thermogravimetric analysis}

TGA was performed with a TA Q-5000 instrument connected to $\mathrm{N}_{2}$ and $\mathrm{CO}_{2}$ gas lines. Samples were kept under vacuum at $40^{\circ} \mathrm{C}$ for $48 \mathrm{~h}$ prior to measurement. The temperature was raised from room temperature to $150{ }^{\circ} \mathrm{C}$ at a rate of $10^{\circ} \mathrm{Cmin}^{-1}$ under $\mathrm{N}_{2}$ flow $\left(40 \mathrm{~mL} \mathrm{~min}{ }^{-1}\right)$, and was kept at $150^{\circ} \mathrm{C}$ for $45 \mathrm{~min}$ to ensure all volatile substances were removed. Then, the temperature was decreased to $50^{\circ} \mathrm{C}\left(10^{\circ} \mathrm{Cmin}^{-1}\right)$ and allowed to equilibrate for $30 \mathrm{~min}$, after which gas was switched to $\mathrm{CO}_{2}\left(100 \mathrm{~mL} \mathrm{~min}^{-1}\right)$ for one hour. The mass change at this stage was used to calculate physical $\mathrm{CO}_{2}$ adsorption. Again, the gas was switched back to $\mathrm{N}_{2}$ while the temperature was held at $50^{\circ} \mathrm{C}$ for one hour (physical desorption), then ramped up to $100^{\circ} \mathrm{C}$ at the rate of $10^{\circ} \mathrm{Cmin}^{-1}$. Measurements were repeated three times. The masses of the ionogel samples in the TGA pan were between 4 and $10 \mathrm{mg}$.

\section{Differential scanning calorimetry}

DSC was conducted to measure the glass transition temperature of the ionogels using a TA Instruments DSC, model Q1000. A cyclic heat/cool/heat method was employed under $50 \mathrm{~mL} \mathrm{~min}^{-1}$ nitrogen flow with heating and cooling rates of $10^{\circ} \mathrm{Cmin}^{-1}$ from -80 to $200^{\circ} \mathrm{C}$. Samples were dried at $60^{\circ} \mathrm{C}$ overnight prior to testing.

\section{Cyclic voltammetry experiments}

The solid-state electrochemical cell described above was placed inside a $50 \mathrm{~mL}$ plastic chamber that was connected to $\mathrm{N}_{2}$ and $\mathrm{CO}_{2}$ gas lines. The gas was allowed to flow for $30 \mathrm{~min}$ prior to each cyclic voltammetry experiment. Tests were performed at $50 \mathrm{mV} \mathrm{s}^{-1}$ from $-0.2 \mathrm{~V}$ to $-1.9 \mathrm{~V}$ vs. $\mathrm{Ag}$ wire using a $\mathrm{CH}$ instruments potentiostat model $650 \mathrm{D}$, USA. 


\section{Acknowledgements}

S.N. and F.D. acknowledge the Australian Research Council Training Centre for the Australian Food Processing Industry in $21^{\text {st }}$ Century for funding (Project Number IC140100026). S.N., T.B., A.W., D.L.O., and G.G.W. acknowledge funding from the Australian Research Council Centre of Excellence Scheme (Project Number CE 140100012). The authors also acknowledge the Australian National Fabrication Facility (ANFF). S.N. thanks Prof. Geoffrey M. Spinks for his continual inspiration and support as well as the University of Wollongong's Global Challenges Program.

\section{Conflict of interest}

The authors declare no conflict of interest.

Keywords: $\mathrm{CO}_{2}$ capture $\cdot \mathrm{CO}_{2}$ reduction - electrochemical devices $\cdot$ ionogels $\cdot$ poly(ionic liquid) gels

[1] L. C. Tomé, I. M. Marrucho, Chem. Soc. Rev. 2016, 45, 2785-2824.

[2] K. Goto, K. Yogo, T. Higashii, Appl. Energy 2013, 111, 710-720.

[3] Q. Zhuang, B. Clements, J. Dai, L. Carrigan, Int. J. Greenhouse Gas Control 2016, 52, 449-460.

[4] S. Zulfiqar, M. I. Sarwar, D. Mecerreyes, Polym. Chem. 2015, 6, 6435-6451

[5] J. M. Huck, L.-C. Lin, A. H. Berger, M. N. Shahrak, R. L. Martin, A. S. Bhown, M. Haranczyk, K. Reuter, B. Smit, Energy Environ. Sci. 2014, 7, 4132-4146.

[6] Y. Zeng, R. Zou, Y. Zhao, Adv. Mater. 2016, 28, 2855-2873.

[7] B.-J. Yao, L.-G. Ding, F. Li, J.-T. Li, Q.-J. Fu, Y. Ban, A. Guo, Y.-B. Dong, ACS Appl. Mater. Interface 2017, DOI: https://doi.org/10.1021/ acsami.7b12697.

[8] Y. Ban, Z. Li, Y. Li, Y. Peng, H. Jin, W. Jiao, A. Guo, P. Wang, Q. Yang, C. Zhong, W. Yang, Angew. Chem. Int. Ed. 2015, 54, $15483-$ 15487; Angew. Chem. 2015, 127, 15703-15707.

[9] J. Liu, X. Hou, H. B. Park, H. Lin, Chem. Eur. J. 2016, 22, 1598015990.

[10] J. Guzmán, C. Ortega-Guevara, R. G. de León, R. Martínez-Palou, Chem. Eng. Technol. 2017, DOI: https://doi.org/10.1002/ ceat.201600593.

[11] Y. Huang, G. Cui, Y. Zhao, H. Wang, Z. Li, S. Dai, J. Wang, Angew. Chem. Int. Ed. 2017, 56, 13293-13297; Angew. Chem. 2017, 129, $13478-13482$.

[12] X. Zhu, M. Song, Y. Xu, ACS Sustainable Chem. Eng. 2017, 5, $8192-$ 8198.

[13] F. K. Chong, V. Andiappan, D. K. S. Ng, D. C. Y. Foo, F. T. Eljack, M. Atilhan, N. G. Chemmangattuvalappil, ACS Sustainable Chem. Eng. 2017, 5, 5241-5252.

[14] X. Luo, Y. Guo, F. Ding, H. Zhao, G. Cui, H. Li, C. Wang, Angew. Chem. Int. Ed. 2014, 53, 7053-7057; Angew. Chem. 2014, 126, 7173 7177.

[15] G. Cui, J. Wang, S. Zhang, Chem. Soc. Rev. 2016, 45, 4307-4339.

[16] M. Gonzalez-Miquel, J. Bedia, C. Abrusci, J. Palomar, F. Rodriguez, J. Phys. Chem. B 2013, 117, 3398-3406.

[17] J. F. Brennecke, B. E. Gurkan, J. Phys. Chem. Lett. 2010, 1, 34593464.

[18] K. M. Gupta, Y. Chen, J. Jiang, J. Phys. Chem. C 2013, 117, $5792-$ 5799 .
[19] K. N. Ruckart, R. A. O'Brien, S. M. Woodard, K. N. West, T. G. Glover, J. Phys. Chem. C 2015, 119, 20681-20697.

[20] Z. Dai, R. D. Noble, D. L. Gin, X. Zhang, L. Deng, J. Membr. Sci. 2016, 497, 1-20.

[21] V. Hiremath, A. H. Jadhav, H. Lee, S. Kwon, J. G. Seo, Chem. Eng. J. 2016, 287, 602-617.

[22] W. Zhao, G. He, F. Nie, L. Zhang, H. Feng, H. Liu, J. Membr. Sci. 2012, 411-412, 73-80.

[23] D. Nikolaeva, I. Azcune, E. Sheridan, M. Sandru, A. Genua, M. Tanczyk, M. Jaschik, K. Warmuzinski, J. C. Jansen, I. F. J. Vankelecom, J. Mater. Chem. A 2017, 5, 19808-19818.

[24] T. Wang, K. Ge, Y. Wu, K. Chen, M. Fang, Z. Luo, Energy Fuels 2017, 31, 11127-11133.

[25] S. M. Morozova, A. S. Shaplov, E. I. Lozinskaya, D. Mecerreyes, H. Sardon, S. Zulfiqar, F. Suárez-García, Y. S. Vygodskii, Macromolecules 2017, 50, 2814-2824.

[26] T. Wang, C. Hou, K. Ge, K. S. Lackner, X. Shi, J. Liu, M. Fang, Z. Luo, J. Phys. Chem. Lett. 2017, 8, 3986-3990.

[27] M. G. Cowan, D. L. Gin, R. D. Noble, Acc. Chem. Res. 2016, 49, $724-$ 732.

[28] S. Soll, Q. Zhao, J. Weber, J. Yuan, Chem. Mater. 2013, 25, 30033010 .

[29] L. C. Tomé, D. Mecerreyes, C. S. R. Freire, L. P. N. Rebelo, I. M. Marrucho, J. Membr. Sci. 2013, 428, 260-266.

[30] L. C. Tomé, M. Isik, C. S. R. Freire, D. Mecerreyes, I. M. Marrucho, J. Membr. Sci. 2015, 483, 155-165.

[31] M. G. Cowan, M. Masuda, W. M. McDanel, Y. Kohno, D. L. Gin, R. D. Noble, J. Membr. Sci. 2016, 498, 408-413.

[32] G. Zhang, G. Wei, Z. Liu, S. R. J. Oliver, H. Fei, Chem. Mater. 2016, $28,6276-6281$.

[33] J. Choi, T. M. Benedetti, R. Jalili, A. Walker, G. G. Wallace, D. L. Officer, Chem. Eur. J. Chem. A 2016, 22, 14158-14161.

[34] Z. Wang, G. Yang, Z. Zhang, M. Jin, Y. Yin, ACS Nano 2016, 10, $4559-4564$.

[35] S. Gao, X. Jiao, Z. Sun, W. Zhang, Y. Sun, C. Wang, Q. Hu, X. Zu, F. Yang, S. Yang, L. Liang, J. Wu, Y. Xie, Angew. Chem. Int. Ed. 2016, 55, 698-702; Angew. Chem. 2016, 128, 708-712.

[36] X. Min, M. W. Kanan, J. Am. Chem. Soc. 2015, 137, 4701-4708.

[37] S. Naficy, S. Kawakami, S. Sadegholvaad, M. Wakisaka, G. M. Spinks, J. Appl. Polym. Sci. 2013, 130, 2504-2513.

[38] L. R. G. Treloar in The Physics of Rubber Elasticity, Oxford University Press, Oxford, 1975.

[39] M. Delavar, A. A. Ghoreyshi, M. Jahanshahi, S. Khalili, N. Nabian, RSC Adv. 2012, 2, 4490-4497.

[40] M. J. Muldoon, S. N. V. K. Aki, J. L. Anderson, J. K. Dixon, J. F. Brennecke, J. Phys. Chem. B 2007, 111, 9001-9009.

[41] A. Wilke, J. Yuan, M. Antonietti, J. Weber, ACS Macro Lett. 2012, 1, 1028-1031.

[42] T. Hatsukade, K. Kuhl, E. Cave, D. Abram, T. Jaramillo, Phys. Chem. Chem. Phys. 2014, 16, 13814-13819.

[43] B. A. Rosen, W. Zhu, G. Kaul, A. Salehi-Khojin, R. I. Masel, J. Electrochem. Soc. 2012, 160, H138-H141.

[44] J. Yang, Z. Hua, T. Wang, B. Wu, G. Liu, G. Zhang, Langmuir 2015, $31,6078-6084$

[45] K. Nakamura, T. Saiwaki, K. Fukao, T. Inoue, Macromolecules 2011, 44, 7719-7726.

[46] G. Sauerbrey, Z. Phys. 1959, 155, 206-222.

[47] T. M. Benedetti, R. M. Torresi, Langmuir 2013, 29, 15589-15595.

Manuscript received: September 18, 2017

Revised manuscript received: October 29, 2017

Accepted manuscript online: November 23, 2017

Version of record online: February 16, 2018 